\title{
SILICA SUPPORTED RHODIUM METAL NANOPARTICLES STABILIZED WITH (-)-DIOP. EFFECT OF LIGAND CONCENTRATION AND METAL LOADING ON THE ENANTIOSELECTIVE HYDROGENATION OF KETONES
}

\author{
DORIS RUIZ ${ }^{*}$, CLAUDIO MELLA' ${ }^{1}$ JOSÉ L.G. FIERRO² AND PATRICIO REYES ${ }^{1}$ \\ ${ }^{1}$ Universidad de Concepción, Facultad Ciencias Químicas, Edmundo Larenas 129, Concepción, Chile. \\ ${ }^{2}$ Instituto de Catálisis y Petroleoquímica, CSIC, Marie Curie 2, Cantoblanco 28049 Madrid, Spain.
}

(Received: July 12, 2012 - Accepted: July 23, 2012)

\begin{abstract}
Supported nanoparticles (NPs) in presence of chiral ligand (L) were synthesized for their use in enantioselective hydrogenation reactions. Catalysts were obtained by chemical reduction from rhodium chloride hydrate, $\mathrm{RhCl}_{3} \times 3 \mathrm{H}_{2} \mathrm{O}$, in presence of (-)-DIOP ligand ((4R,5R)-4,5-Bis(diphenylphosphino-methyl)2,2-dimethyl-1,3-dioxolane) that allows to control NPs growing and to obtain solids having chiral surfaces. Chirally stabilized rhodium $\mathrm{NPs}$ on $\mathrm{SiO}_{2}$ were characterized using techniques such as: TEM, electron diffraction, EDS, nitrogen adsorption-desorption isotherms and XPS.

This work includes the study of some variables such as metal loading and ligand concentration and their effect in metal core sizes, catalytic activity and enantioselectivity. Catalysts properties have also been evaluated in the hydrogenation of substrates: acetophenone (AP), 1-phenyl-1,2-propanedione (PPD), 3,4-hexanedione (HD), 2,3-butanedione (BD) and ethyl pyruvate (EP) as reaction test.

Ligand plays a fundamental role in the synthesis of NPs and enantioselectivity in hydrogenations reactions. That is, due to it generates metal particle size $<$ $5.8 \mathrm{~nm}$ compared with unstabilized systems that generate average diameter around $14 \mathrm{~nm}$. Results indicate increased activity in catalytic systems obtained from the stabilization of NPs. Enantioselectivity levels reach values up to $53 \%$ due to the chiral ligand is on the catalysts surface.
\end{abstract}

Keywords: chiral ligand, (-)-DIOP, enantioselective hydrogenation, $\mathrm{Rh} / \mathrm{SiO}_{2}$, stabilized nanoparticles.

\section{INTRODUCTION}

The asymmetric synthesis has gained importance since 2001 when it was awarded the Nobel Prize in Chemistry to Knowles, Noyori and Sharples by scientific contributions in the field of asymmetric homogeneous catalysis ${ }^{1}$. Since then, and due to a growing demand for enantiomerically pure products for industry, there has been an attempt to homogeneous asymmetric hydrogenation of substrates for the production of chiral products as herbicides, insecticides, food, fragrances and especially drugs ${ }^{2,3}$.

Even though asymmetric catalysis has been studied in homogeneous, heterogeneous and enzymatic phase, currently most of the processes to get chiral products are conducted by homogeneous processes, because the catalysts have shown to be extremely efficient and selective. Nowadays important efforts have focused toward the "heterogenization" of the homogeneous asymmetric catalysis or to develop strategies to immobilize chiral NPs on solid supports to achieve simpler and more efficient catalysts able to be used in consecutive cycles and ideally in continuous processes ${ }^{4-6}$.

Catalysts used in fine chemical reactions are mainly noble metals on supports such as $\mathrm{SiO}_{2}, \mathrm{Al}_{2} \mathrm{O}_{3}$, among others. In recent years, the interest in the catalytic properties of metal colloids has increased, due to the high metallic surface of NPs includes a large number of metal atoms available to the substrate ${ }^{7}$. NPs of different metals have been assayed as catalysts in hydrogenation reactions of aromatic hydrocarbons ${ }^{8-10}$ and recently it has been extended to enantioselective hydrogenation reactions ${ }^{11-16}$, hydroformylation and allylic alkylation ${ }^{17-21}$.

Usually traditional synthesis generates colloids diameter higher than 10 $\mathrm{nm}$. Recently it has been developed stabilization processes that generate NPs diameters from 1 to $10 \mathrm{~nm}$. Small diameters and high reproducibility in the formation of metallic particles are related with the addition of stabilizers, which interacts with metal during its reduction to generate particular properties in the material, i.e. chiral surface in NPs with specific shape and composition ${ }^{22-29}$.

The aim of the present work is to study the synthesis of colloids by a method for stabilizing $\mathrm{NPs}^{30-32}$. Stabilization is carried out with a chiral agent in different amounts to obtain asymmetric surface and thus to generate particles of small metal diameter. Catalysts with different ligand concentration and metal loading have been used as catalysts in enantioselective hydrogenation reactions of AP, PPD, HD, BD and EP as test reaction. These substrates are interesting due to the applications that have some of its (R)-product of hydrogenation ${ }^{33-3.3}$ in synthesis of chiral drugs. Thus, (R)-1-hydroxy-1-phenylpropan-2-one, product of PPD hydrogenation, is a precursor for the production of ephedrine and analogues used as a nasal and bronchial decongestant among others ${ }^{36}$.

\section{EXPERIMENTAL}

\section{General}

Rhodium NPs catalysts stabilized with (-)-DIOP on $\mathrm{SiO}_{2}$ were synthesized in inert atmosphere of argon at $\mathrm{pH}=8$ to prevent the decomposition of phosphorus ligand (-)-DIOP (see Fig. 1a).

Prochiral substrates (PPD, BD, EP, HD and AP in Fig.1 b-f) and solvents used in enantioselective hydrogenations were previously purified by distillation. (-)-DIOP was used as received.

Rhodium trichloride hydrate $\left(\mathrm{RhCl}_{3} \times 3 \mathrm{H}_{2} \mathrm{O}\right)$, methyl tetraoctylammonium (TOAB), (-)-DIOP and substrates such as EP, PPD, BD and HD were supplied by Aldrich. Chloroform, cyclohexane and sodium borohydride $\left(\mathrm{NaBH}_{4}\right)$ by Merck, AP for Fluka and $\mathrm{H}_{2}(99.995 \%)$ was supplied by $A G A$.

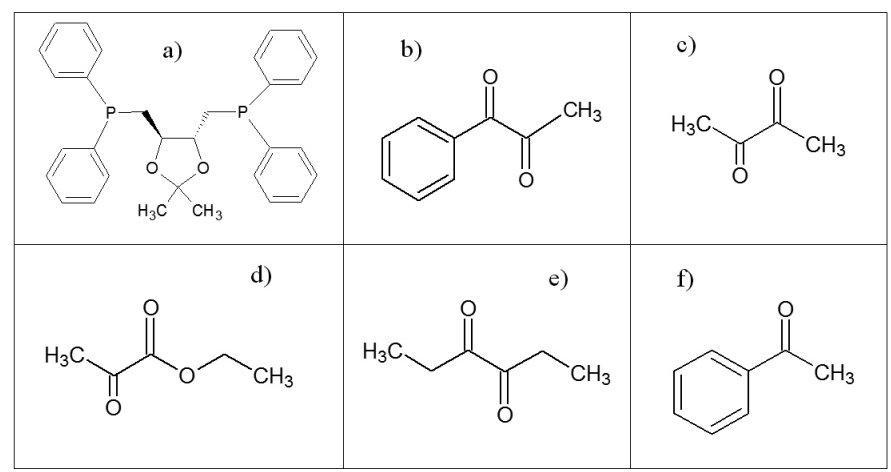

Figure 1. Chiral ligand a) (-)-DIOP and prochiral substrates b) PPD, c) $\mathrm{BD}$, d) $\mathrm{EP}$, e) $\mathrm{HD}$ and f) AP used in NPs synthesis and enantioselective hydrogenations respectively.

\section{Catalysts synthesis}

Stabilized NPs have been synthesized at room temperature for addition of $\mathrm{RhCl}_{3} \times 3 \mathrm{H}_{2} \mathrm{O}$ in $2 \mathrm{~mL}$ of distilled $\mathrm{H}_{2} \mathrm{O}$. $\mathrm{Rh}^{3+}$ dissolution forms a biphasic system with $2 \mathrm{~mL}$ of TOAB dissolved in $2 \mathrm{~mL}$ of chloroform. After $1 \mathrm{~h}$ of stirring in an inert atmosphere (-)-DIOP dissolved in $25 \mathrm{~mL}$ of $\mathrm{CH}_{2} \mathrm{Cl}_{2}$ was added. Prior to incorporation of ligand the $\mathrm{pH}$ of the solution was adjusted to alkaline $(\mathrm{pH}=8.0)$ with a saturated solution of $\mathrm{NaHCO}_{3}\left(100 \mathrm{~g} \times \mathrm{L}^{-1}\right)$, to avoid 
the decomposition of (-)-DIOP. After 30 min under stirring $\mathrm{NaBH}_{4}$, as metal reducer, was added to the $\mathrm{Rh}^{3+}$-L system and stirred for $3 \mathrm{~h}$ in argon at $298 \mathrm{~K}$. The amount of TOAB and $\mathrm{NaBH}_{4}$ was 0.067 and $0.922 \mathrm{mmol}$ respectively and in the study of the effect of ligand concentration, added to NPs synthesis, the amount of (-)-DIOP (on $1.0 \mathrm{wt} \% \mathrm{Rh}$ ) was varied from 0.05 to $0.20 \mathrm{mmol}$ and metal loading was studied in the range of 0.5 to $1.5 \mathrm{wt} \% \mathrm{Rh}(\mathrm{L}=0.15 \mathrm{mmol})$ following procedures reported in literature ${ }^{31-32}$. The NPs-L obtained in all cases were washed $\left(3 \times 25 \mathrm{~mL} \mathrm{H}_{2} \mathrm{O}\right)$, filtered under vacuum and stored in an inert atmosphere.

The catalysts were labeled as: $0.5 \mathrm{Rh}-3 \mathrm{~L}$ to $1.5 \mathrm{Rh}-3 \mathrm{~L}$ according to weigh percent of metal and $1.0 \mathrm{Rh}-1 \mathrm{~L}$ to $1.0 \mathrm{Rh}-4 \mathrm{~L}$ in relation to ligand concentration added on NPs synthesis.

A stabilized dispersion of NPs in appropriate amount, according to $\mathrm{wt} \%$ of metal expected on the support, was deposited by impregnation on $\mathrm{SiO}_{2}$ (BASF, $\left.147 \mathrm{~m}^{2} \times \mathrm{g}^{-1}\right)$ at $40^{\circ} \mathrm{C}$. Then, the solvent was removed under vacuum.

\section{Catalysts characterization}

X-ray photoelectron spectroscopy (XPS) studies were performed in a Fisons Escalab 200R spectrometer with a Mg Ka X-ray radiation $(h v=1253.6$ $\mathrm{eV}$ ) operated at $10 \mathrm{~mA}$ and $12 \mathrm{kV}$. Prior analysis, the samples were pretreated in hydrogen at room temperature.

Metal particle size was determined by transmission electron microscopy (TEM) in a JEOL JEM-1200 model EXII. Energy-dispersive X-ray spectroscopy (EDS), Electron Diffraction (ED) and the patterns of the samples were obtained in the same equipment.

Nitrogen adsorption-desorption isotherms at $77 \mathrm{~K}$ were performed in a Micromeritics ASAP 2010 (CHEMI).

The analysis of reagents and products was followed by chiral GC analysis. Conversion and optical yield, expressed as enantiomeric excess, $(\%)$ ee $=([R]-$ $[S]) /([R]+[S]) \times 100$, were calculated from analysis in a GCMS chromatograph SHIMADZU GC-MS-QP5050 equipped with a chiral column Beta DEX
225 (Supelco) of $30 \mathrm{~m}$ long x $0.25 \mathrm{~mm}$ diameter with helium as carrier gas. Products and reactants were determined by comparison of the retention time with the pure commercial samples.

\section{Enantioselective hydrogenations reactions and recycling}

Enantioselective hydrogenation reactions were carried out in a semibatch reactor stainless steel coated with Teflon in $50 \mathrm{~mL}$ of cyclohexane, 40 bar of $\mathrm{H}_{2}$ pressure, $298 \mathrm{~K}$, stirring speed of $800 \mathrm{rpm}$ and molar ratio [substrate/metal] on the range of 60 to 200 approximately. The experimental conditions were selected to avoid transfer limitations.

A study of recycling in enantioselective hydrogenation of PPD was performed in the same catalytic reaction under conditions previously described. The catalysts were separated by filtration of the prior reaction, washed repeatedly three times with $20 \mathrm{~mL}$ of pentane and dried by solvent extraction. Recovery of catalysts was carried out in argon atmosphere.

Substrate, solvent and recovered catalysts were added to the batch reactor and carried out similarly to that described previously.

\section{RESULTS AND DISCUSSION}

\section{Catalysts characterization}

Analysis of $\mathrm{N}_{2}$ adsorption-desorption isotherms by B.E.T and BJH method allowed to determine specific surface and pore diameter distribution for the catalysts studied. As shown in Table 1, the studied variable, metal content and amount of modifier, did not affect significantly the textural properties of catalysts. The specific surface area ranged from 128 to $147\left(\mathrm{~m}^{2} \times \mathrm{g}^{-1}\right)$ and average pore diameters from 17 to $23 \mathrm{~nm}$. Rh-L/SiO catalysts have type IV isotherm according to the classification Brunauer, Deming, Deming and Teller (B.D.D.T). Isotherms with this kind of hysteresis loop are characteristic of mesoporous solids with cylindrical pore geometry for all samples. These characteristics are appropriate for catalytic applications.

Table 1. Characterization of Rh- $\mathrm{L} / \mathrm{SiO}_{2}$ catalysts. Effect of: (a) metallic loading and (b) ligand concentration on particle size (d), dispersion $(D), \mathrm{S}_{\mathrm{BET}}$ and pore diameter.

\begin{tabular}{|c|c|c|c|c|c|c|c|c|c|c|c|}
\hline \multicolumn{9}{|c|}{ (a) Metallic loading } & \multicolumn{6}{c|}{ (b) Ligand concentration } \\
\hline \%Rh & Catalyst & $\mathbf{d}_{\text {TEM }}(\mathrm{nm})$ & $\mathbf{D}$ & $\begin{array}{c}\mathbf{S}_{\text {B.E.T }} \\
\left(\mathrm{m}^{2} \times \mathrm{g}^{-1}\right)\end{array}$ & $\mathbf{d}_{\text {pore }}(\mathrm{nm})$ & $\begin{array}{c}(-) \text { DIOP, } \\
\mathrm{mmol}\end{array}$ & Catalyst & $\mathbf{d}_{\text {TEM }}(\mathrm{nm})$ & $\mathbf{D}^{\mathbf{D}}$ & $\begin{array}{c}\mathbf{S}_{\text {B.E.T }} \\
\left(\mathrm{m}^{2} \times \mathrm{g}^{-1}\right)\end{array}$ & $\begin{array}{c}\mathbf{d}_{\text {pore }} \\
(\mathrm{nm})\end{array}$ \\
\hline 0.5 & $0.5 \mathrm{Rh}-3 \mathrm{~L}$ & 3.9 & 0.24 & 134 & 23 & 0.05 & $1.0 \mathrm{Rh}-1 \mathrm{~L}$ & 5.8 & 0.16 & 143 & 19 \\
1.0 & $1.0 \mathrm{Rh}-3 \mathrm{~L}$ & 4.8 & 0.19 & 147 & 17 & 0.10 & $1.0 \mathrm{Rh}-2 \mathrm{~L}$ & 5.1 & 0.18 & 135 & 22 \\
1.5 & $1.5 \mathrm{Rh}-3 \mathrm{~L}$ & 5.3 & 0.17 & 128 & 17 & 0.15 & $1.0 \mathrm{Rh}-3 \mathrm{~L}$ & 4.8 & 0.19 & 140 & 18 \\
\end{tabular}

a) Effect of metal loading using $0.15 \mathrm{mmol}(-)$-DIOP (3L) and b) Effect of ligand concentration on 1.0wt\% of Rh (1.0Rh) catalysts. Dispersion (D) was calculated from $\mathrm{d}_{\text {TFM }}$ and Rh metallic surface of $436\left(\mathrm{~m}^{2} \times \mathrm{g}^{-1}\right.$ metal).

Energy Dispersive X-ray Spectroscopy and Electron Diffraction were performed in order to verify the components present in Rh catalysts. Figure 2a shows electron diffraction and EDS spectrums for 1.0Rh-3L. In all cases it was confirmed that the reduction method is effective and metal component of the catalysts is mainly in the zero reduction state. The diffraction showed a crystallographic direction with higher intensity of the plane (111) and an interplanar spacing of $2.196 \mathrm{~A}^{\circ}$. Under the same conditions used for electron diffraction, EDS analysis from counts versus energy allowed to verify the presence of $\mathrm{Rh}$ in all catalysts, see figure $2 \mathrm{~b}$. The study was performed in the range of 1 to $20 \mathrm{keV}$ and despite the low percentage of metal in the catalysts, rhodium generated peaks of intensity 3 and $20 \mathrm{keV}$ referred to the internal standard $\mathrm{Cu}(8-9 \mathrm{keV})$.

Rh particle size and metal dispersion were obtained from TEM and the results are compiled in Table 1. The average particle size for catalysts, prepared in presence of $0.15 \mathrm{mmol}$ of (-)-DIOP as chiral modifier, increase from 3.9 to $5.3 \mathrm{~nm}$ according as metal loading vary from 0.5 to $1.5 \%$ (see Fig. 3), whereas metal dispersion decreases as Rh content increases. The observed trend can be understood taking into account that there is a strong tendency to the growth of clusters when there are low amounts of ligand in colloidal synthesis. This behavior is expected for the series due to the stabilizer containing phosphorus which interacts with $\mathrm{Rh}$ during reduction with $\mathrm{NaBH}_{4}$, limiting the metal-metal agglomeration.
The effect of ligand concentration on the metal particle size was carried out with the $1.0 \mathrm{wt} \%$ of $\mathrm{Rh}$. As expected, the ligand plays an important role to stabilize the crystallites formed during the reduction and therefore if the concentration of the stabilizer increases the average metal particle size decreases. In absence of ligand, diameters up $14 \mathrm{~nm}$ were obtained.

Surface studies of Rh catalysts were performed by XPS. Binding energies (BE) have been obtained in comparison to $\mathrm{C} 1 \mathrm{~s}$ of $284.9 \mathrm{eV}$.

$R h 3 d_{52}$ core level spectra showed the presence of $R h$ in two different oxidation states. $\mathrm{Rh}^{\mathrm{o}}$ at $307.3 \mathrm{eV}$ and $\mathrm{Rh}^{\mathrm{d}+}$ at $309.9 \mathrm{eV}$, see figure 4 . Rhodium is mainly in a reduced state (see table 2), confirming that the reduction method is effective, however, a fraction close to $30 \%$ of $\mathrm{Rh}^{\mathrm{d}+}$ are present in most of catalysts. This later species are important because they can contribute to polarize the $\mathrm{C}=\mathrm{O}$ bond of the substrates making easier it hydrogenation ${ }^{37-39}$. 

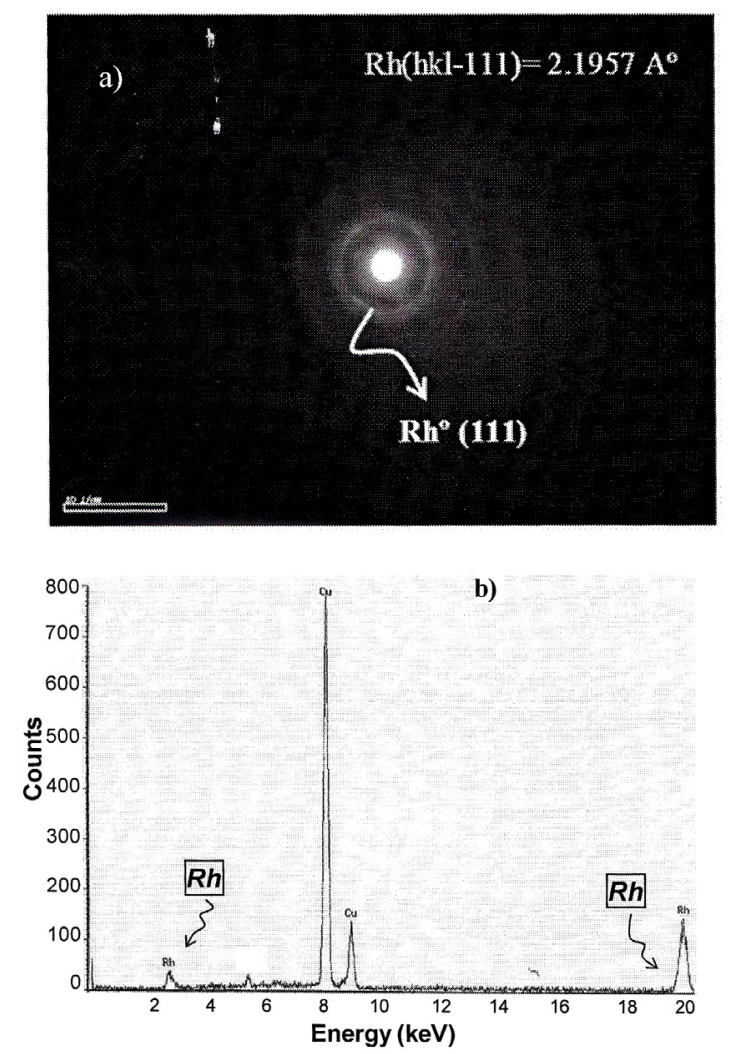

Figure 2. a) Electron diffraction and b) EDS spectrum for 1.0Rh-3L catalyst.
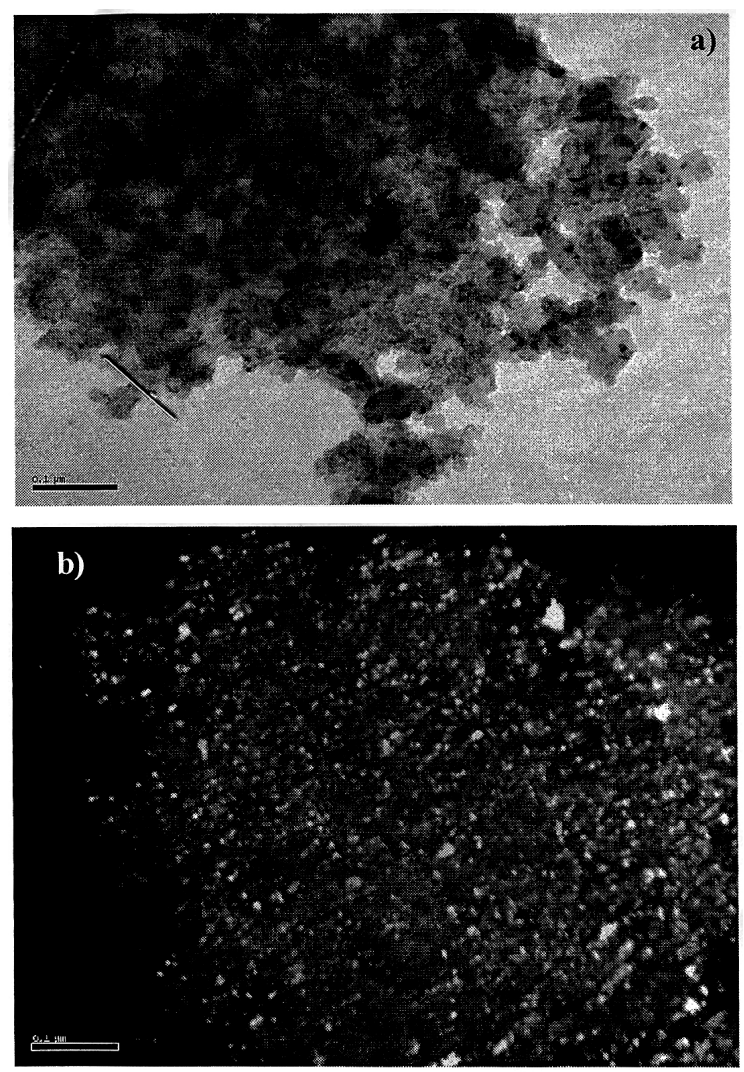

Figure 3. TEM images for a) $1.0 \mathrm{Rh}-4 \mathrm{~L}$ and b) $1.0 \mathrm{Rh}-3 \mathrm{~L}$ catalysts.
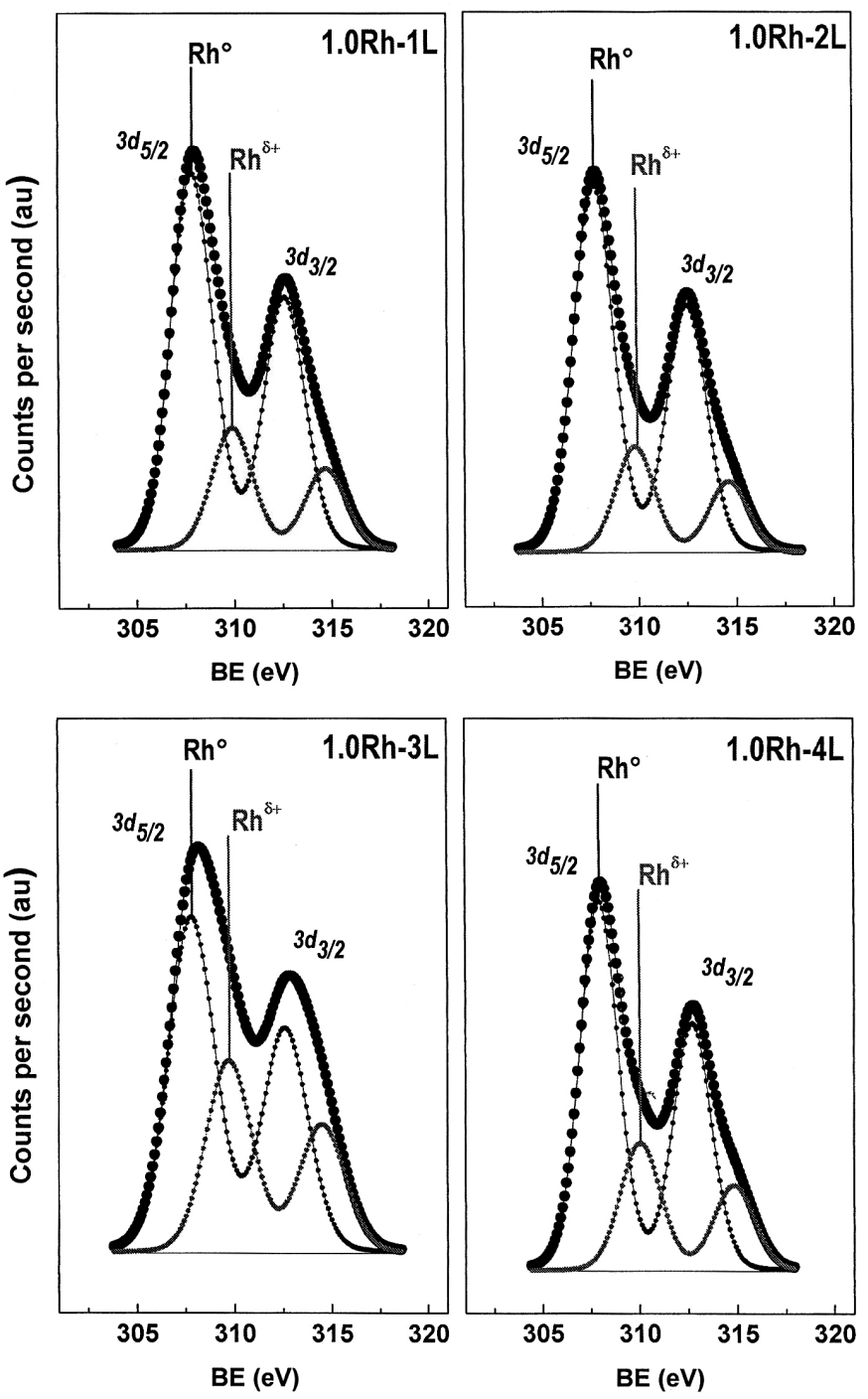

Figure 4. Binding energies $(\mathrm{eV})$ of internal levels of $\mathrm{Rh}$ catalysts synthesized in different chiral ligand concentrations a) $1.0 \mathrm{Rh}-1 \mathrm{~L} \mathrm{~b}$ ) $1.0 \mathrm{Rh}-2 \mathrm{~L}$ c) $1.0 \mathrm{Rh}-3 \mathrm{~L}$ and d) $1.0 \mathrm{Rh}-4 \mathrm{~L}$.

In the series of catalysts with $0.15 \mathrm{mmol}(-)$-DIOP and different Rh content, the $\mathrm{Rh} / \mathrm{Si}$ atomic surface ratio increases with $\mathrm{Rh}$ content on the catalysts. The observed enhancement in the $\mathrm{Rh} / \mathrm{Si}$ atomic surface ratio in a factor of 18 as the bulk ratio increases almost 3 times is indicative of changes in the location of metallic crystals. Thus, the catalyst with lower Rh content generates smaller chiral metallic crystals which remain mainly inside the pore structure of the support. As the metal loading increases, a higher fraction of the NPs are in external positions of the support and consequently easier detectable by XPS. Similar trends can explain the $\mathrm{Rh} / \mathrm{Si}$ atomic surface values obtained in the series with variable ligand content. As was previously reported, an increase in the ligand concentration lead to smaller metal NPs, thus this tiny particles can be mainly located inside the pores structure of the support and therefore the detected $\mathrm{Rh} / \mathrm{Si}$ surface ratio also decreases (see table 2). 
Table 2. Binding energies of $3 \mathrm{~d}_{5 / 2}$ and $\mathrm{Rh} / \mathrm{Si}$ surface and bulk atomic surface ratios of Rh catalysts.

\begin{tabular}{|c|c|c|c|}
\hline Catalyst & $\mathbf{R h ~ 3 d}_{5 / 2}(\mathbf{B E}, \mathbf{e V})$ & $\mathbf{( R h} / \mathbf{S i})_{s}$ & $(\mathbf{R h} / \mathbf{S i})_{b}$ \\
\hline $0.5 \mathrm{Rh}-3 \mathrm{~L}$ & $307.3(100)$ & 0.0016 & 0.00293 \\
\hline 1.0Rh-3L & $\begin{array}{l}307.7(65) \\
309.8(35)\end{array}$ & 0.0056 & 0.00589 \\
\hline 1.5Rh-3L & $\begin{array}{l}307.7(77) \\
309.8(23)\end{array}$ & 0.0293 & 0.00888 \\
\hline 1.0Rh-1L & $\begin{array}{l}307.8(75) \\
309.9(25)\end{array}$ & 0.0051 & 0.00589 \\
\hline 1.0Rh-2L & $\begin{array}{l}307.7(78) \\
309.8(22)\end{array}$ & 0.0048 & 0.00589 \\
\hline 1.0Rh-3L & $\begin{array}{l}307.8(67) \\
309.9(33)\end{array}$ & 0.0044 & 0.00589 \\
\hline 1.0Rh-4L & $\begin{array}{l}307.8(73) \\
309.9(27)\end{array}$ & 0.0019 & 0.00589 \\
\hline
\end{tabular}

\section{Enantioselective hydrogenations}

The asymmetric hydrogenation of EP was performed as a reaction test to evaluate the activity and enantioselectivity of all synthesized catalysts (see Fig. 5).

It can be seen that the reaction progress continuously according a pseudofirst order reaction. The conversion levels reached by catalyst with higher metal loading $(1.5 \mathrm{Rh}-3 \mathrm{~L})$ are similar to $1.0 \mathrm{Rh}-3 \mathrm{~L}$ whereas the $0.5 \mathrm{Rh}-3 \mathrm{~L}$ catalyst displayed lower conversion. This may be explained in terms of availability metal active sites which in turns depend on metal dispersion and location of metal crystals. With regard to the enantioselectivity, in the enantioselective hydrogenation of EP, it was found a preferential formation of $(R)$-ethyl lactate (Fig. 6a).

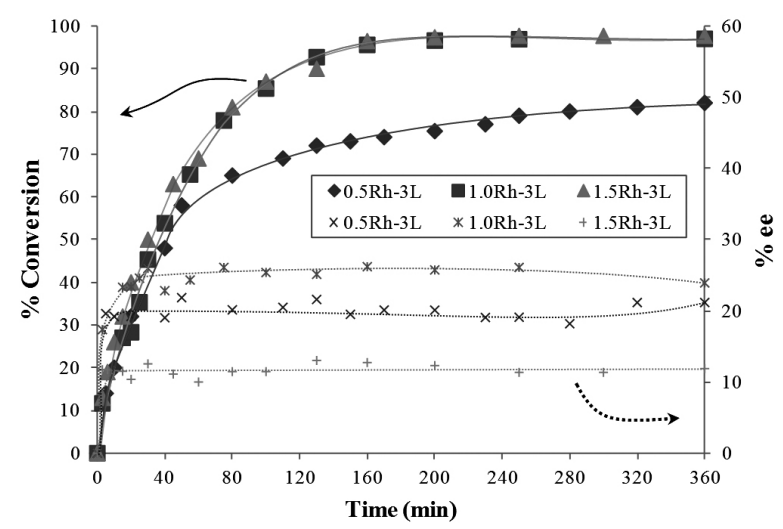

Figure 5. Evolution of the conversion and enantioselectivity on time for EP hydrogenation on $100 \mathrm{mg}$ of Rh catalysts, $0.02 \mathrm{~mol}^{\times} \mathrm{L}^{-1}$ of EP in cyclohexane at $298 \mathrm{~K}$ and 40 bar of $\mathrm{H}_{2}$.

The ee do not change significantly with the conversion level. In the study of metal loading, 1.0Rh-3L catalyst displayed the highest ee value, $26 \%$. $1.5 \mathrm{Rh}-3 \mathrm{~L}$ catalyst compared to $1.0 \mathrm{Rh}-3 \mathrm{~L}$, contains an excess of $50 \% \mathrm{Rh}$ atoms, similar metal dispersion but a lower ligand/metal ratio, therefore a lower ee value can be expected. On the other hand, in spite of the $0.5 \mathrm{Rh}-3 \mathrm{~L}$ catalyst presents the highest ligand/metal ratio, its metal dispersion is also the highest and consequently the metal particle size is the smallest which allow to locate them in the interior of the pore structure, and the accessibility of the substrate to the chiral centers is more limited. Thus, this catalyst should exhibit the lowest activity and the highest selectivity.

From the evolution of substrate concentration with time, mainly during the first 60 min the pseudo first order rate constant was obtained and the results are compiled in Table 3.
Table 3. Conversion levels and enantioselectivity in the hydrogenation of EP $0.02 \mathrm{~mol} \times \mathrm{L}^{-1}$ using $100 \mathrm{mg}$ of Rh catalysts in cyclohexane at $298 \mathrm{~K}$ and 40 bar of $\mathrm{H}_{2}$.

\begin{tabular}{|c|c|c|c|c|}
\hline Catalyst & $\begin{array}{c}\% \\
\text { Conversion }\end{array}$ & $\begin{array}{c}\boldsymbol{k} / 10^{-5} \\
\left(\mathrm{~min}^{-1} \times g_{\text {cat }}\right. \\
\left.{ }^{l} \times \text { mol }\right)^{b}\end{array}$ & $\begin{array}{c}\boldsymbol{k} \\
\left(\mathrm{min}^{-1} \times a t\right. \\
\left.{ }_{R h} \times \text { molec }\right)^{b}\end{array}$ & $\% \mathrm{ee}^{c}{ }_{\text {max }}$ \\
\hline $0.5 \mathrm{Rh}-3 \mathrm{~L}$ & 82 & 7.9 & 1.63 & 21 \\
\hline 1.0Rh-3L & 97 & 9.0 & 0.93 & 26 \\
\hline $1.5 \mathrm{Rh}-3 \mathrm{~L}$ & 98 & 9.3 & 0.64 & 11 \\
\hline $1.0 \mathrm{Rh}-1 \mathrm{~L}$ & 95 & 7.4 & 0.76 & 19 \\
\hline $1.0 \mathrm{Rh}-2 \mathrm{~L}$ & 91 & 5.8 & 0.60 & 29 \\
\hline $1.0 \mathrm{Rh}-3 \mathrm{~L}$ & 97 & 9.0 & 0.93 & 26 \\
\hline $1.0 \mathrm{Rh}-4 \mathrm{~L}$ & 99 & 8.9 & 0.92 & 27 \\
\hline
\end{tabular}

a $\%$ conversion at $360 \mathrm{~min}$ of reaction. ${ }^{\mathrm{b}}$ Pseudoconstants of first order rate calculated up to $60 \mathrm{~min} .{ }^{\mathrm{c}} \%$ ee referred to the formation of (R)-ethyl lactate.

Figure 6 shows the main products in the enantioselective hydrogenation of HD, BD, PPD and AP. (-)-DIOP as chiral inducer on the surface allows to obtain only R-enantiomers. In the enantioselective hydrogenation of ketones, catalytic activity and enantioselectivity show opposite trends. Thus, substrates easy to hydrogenate usually display a low \%ee. Furthermore, the structure of each substrate affects the catalytic behavior, in lineal diketones prevails activity with respect to enantioselectivity levels, opposite to aromatic ketones.

Table 4 shows the conversion levels of different substrates studied at 420 min of reaction and ee obtained using $1.0 \mathrm{Rh}-3 \mathrm{~L}$ catalyst. It should be mentioned that even though the enantioselectivity levels remains approximately constant with the conversion in the different studied reactions, conversion levels and pseudo constant rate are higher in lineal diketones, however, are lower in enantioselectivity, in line with results already reported ${ }^{33-34}$. On the other hand, aromatic ketones, PPD and AP, show higher \%ee and lower activity, attributed to the structure of the aromatic compounds.

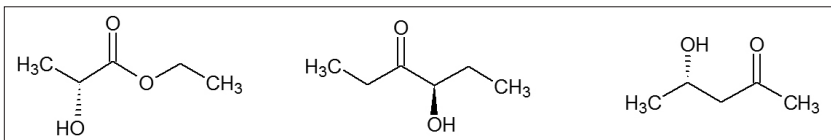

a) (R)-ethyl lactate

b) 4-(R)-hydroxy-3-hexanone c) 3-(R)-hydroxy-2-butanone<smiles>CC(=O)C(O)c1ccccc1</smiles><smiles>CC(O)c1ccccc1</smiles>

d) (R)-1-hydroxy-1-phenylpropan-2-one

e) (R)-phenylethanol

Figure 6. Main products in the enantioselective hydrogenation of a) EP, b) $\mathrm{HD}, \mathrm{c}) \mathrm{BD}, \mathrm{d})$ PPD and e) AP.

Table 4. Pseudo first order rate constants, conversion levels and enantioselectivity in the hydrogenation of $\mathrm{EP}, \mathrm{HD}, \mathrm{BD}, \mathrm{PPD}$ and $\mathrm{AP}$. Conditions: $0.02 \mathrm{~mol} \times \mathrm{L}^{-1}$ on $100 \mathrm{mg}$ of $1.0 \mathrm{Rh}-3 \mathrm{~L}$ catalyst in cyclohexane at $298 \mathrm{~K}$ and 40 bar of $\mathrm{H}_{2}$.

\begin{tabular}{|c|c|c|c|}
\hline Substrate & $\%$ Conversion ${ }^{a}$ & $\begin{array}{c}\boldsymbol{k} / 10^{-5} \\
\left(\mathrm{~min}^{-1} \times g_{\text {cat }}^{-1} \times \mathrm{mol}\right)^{b}\end{array}$ & $\% \mathbf{e e}_{\text {max }}^{c}$ \\
\hline HD & 89 & 6.7 & 26 \\
\hline $\mathrm{BD}$ & 94 & 12.8 & 23 \\
\hline PPD & $\begin{array}{c}72 \\
68^{\mathrm{d} 1} \\
50^{\mathrm{d} 2} \\
45^{\mathrm{d} 3} \\
41^{\mathrm{d} 4} \\
\end{array}$ & $\begin{array}{c}2.6 \\
2.5^{\mathrm{d} 1} \\
1.8^{\mathrm{d} 2} \\
1.6^{\mathrm{d} 3} \\
1.2^{\mathrm{d} 4} \\
\end{array}$ & $\begin{array}{c}53 \\
45^{\mathrm{d} 1} \\
38^{\mathrm{d} 2} \\
37^{\mathrm{d} 3} \\
37^{\mathrm{d} 4}\end{array}$ \\
\hline AP & 88 & 2.3 & 48 \\
\hline
\end{tabular}

a\% Conversion at 420 min of reaction. ${ }^{\mathrm{b}}$ Pseudoconstants of first order rate calculated up to $60 \mathrm{~min}$. ${ }^{\mathrm{c} \%}$ ee referred to the formation of $(R)$-product, see figure $6 .{ }^{\mathrm{d}}$ Results of recycling. 1, 2 and 3 correspond to the cycle number. 
One of the most interesting products in the hydrogenation of substrates is ( $R$ )-1-hydroxy-1-phenylpropan-2-one, from PPD. This compound is commonly known as L-PAC and its importance become because it acts as a key intermediate of various compounds used for treatment of hypotension, nasal decongestants and asthma ${ }^{40}$. It production was preferencial with respect to others products of PPD hydrogenation. During the formation of a new pair of enantiomers in minor amount, the ee values vary reached a maximum of $53 \%$ at 420 minutes of reaction.

Figure 7 shows the reactant consumption and the formation of products in PPD hydrogenation. It can be observed as the diketone is converted, the hydrogenation of both carbonyl bonds may occurs, however, is favoured the hydrogenation of carbonyl group closer to the aromatic ring. After $100 \mathrm{~min}$ of reaction the slight formation of $(S)$ and (R)-2-hydroxy-1-phenylpropan-1-one was observed, but in lower extent.

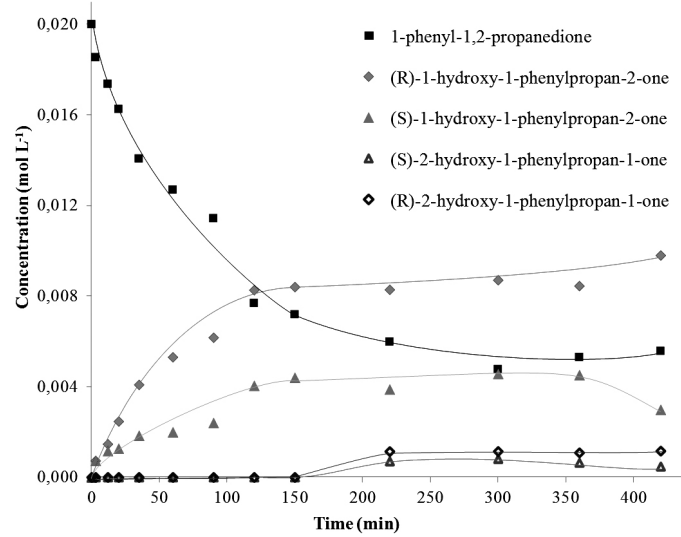

Figure 7. Evolution of the PPD hydrogenation on time. Reaction conditions: $0.02 \mathrm{~mol} \times \mathrm{L}^{-1}$ of substrate, $100 \mathrm{mg}$ of $1.0 \mathrm{Rh}-3 \mathrm{~L}$ catalyst, 40 bar of $\mathrm{H}_{2}$ and $298 \mathrm{~K}$ in cyclohexane as solvent.

One of the most important advantages of heterogeneous catalysis is that the catalyst recycling is easier. In this work, $1.0 \mathrm{Rh}-3 \mathrm{~L}$ catalysts were used in consecutive cycles of PPD hydrogenation without addition of extra chiral inducer.

Catalytic results in the reaction of PPD indicate a decrease in activity by reusing the $1.0 \mathrm{Rh}-3 \mathrm{~L}$ catalyst, however, the conversion reaches high values up to $41 \%$ and $37 \%$ of enantioselectivity at $420 \mathrm{~min}$ of reaction until cycle $\mathrm{N}^{\circ} 4$ compared to 72 y $53 \%$ initial respectively. Table 4 summarizes the obtained results of recycling on PPD and in figure 8 it can also be seen that chiral catalyst shows a deactivation in the successive cycles but with rather slight changes in the enantioselectivity. These changes in activity and enantioselectivity are attributed to small leaching of metal NPs along the cycles.

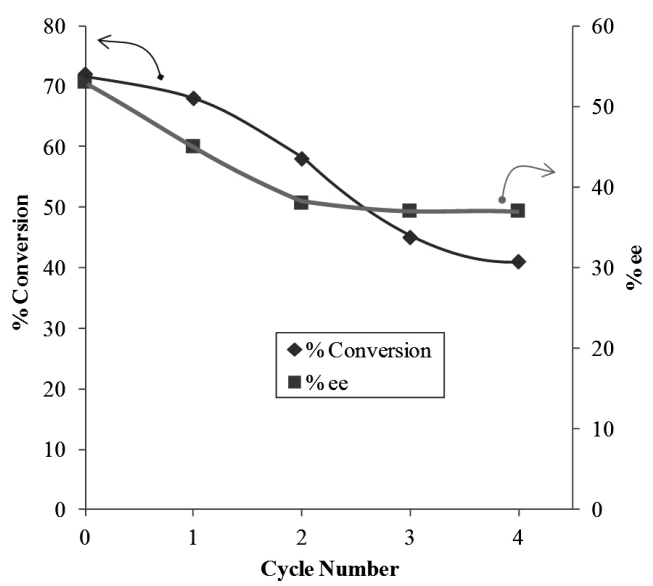

Figure 8. Recycles of 1.0Rh-3L catalyst. Conversion of PPD and ee of (R)-1-hydroxy-1-phenylpropan-2-one. Reactions conditions: $0.02 \mathrm{~mol} \times \mathrm{L}^{-1}$ of PPD over $100 \mathrm{mg}$ of $1.0 \mathrm{Rh}-3 \mathrm{~L}$ catalyst in cyclohexane at $298 \mathrm{~K}$ and $40 \mathrm{bar}$ of $\mathrm{H}_{2}$.
An unmodified catalyst, $1 \% \mathrm{Rh} / \mathrm{SiO}_{2}$, obtained in similar conditions but without (-)-DIOP as stabilizer, was also prepared as comparison with 1.0Rh$3 \mathrm{~L}$. Average particles size of this catalyst was higher as consequence of it was prepare in absence of the stabilizer ligand and therefore the growing of the metal particle is higher. Additionally, the lack of chiral surface leads to the racemic mixture. These catalytic tests were performed only on the hydrogenation in similar conditions of PPD substrate.

\section{CONCLUSIONS}

The hydrogenation of prochiral substrates at 40 bar and $298 \mathrm{~K}$ was studied on different $\mathrm{Rh}$ chiral catalysts. The obtained results indicate that catalysts synthesized under mild conditions allow to obtain active and selective NPs on $\mathrm{SiO}_{2}$ in asymmetric hydrogenation, without further treatment, because the surface contains chirally modified metal sites.

The variation of metal loading in the catalysts allows a slight change in catalytic activity, and it was also found that the concentration of chiral ligand added in the synthesis of Rh NPs significantly affects the metal size and the enantioselectivity of each system in particular.

The reuse of catalyst shows high activity and enantioselectivity in a first recycle decreasing slightly with increasing the amount of recycling. These changes are explained in terms of small leaching of metal NPs.

\section{REFERENCES}

1. B.D. Vineyard, W.S. Knowles, M.J. Sabacky, G.L. Bachman, D.J. Weinkauff, J. Am. Chem. Soc. 99, 5946, (1977).

2. R.A. Sheldon, Chirotechnology. Industrial Synthesis of Optically Active Compounds, Marcel Dekker, Inc., New York, 1993; pp. 173204.

3. A.N. Collins, G.N. Sheldrake, J. Crosby. Chirality in Industry. Vol I, Vol II, Jhon Wiley, Chichester, 1992 and 1997.

4. S.A. Matlin, W.J. Lough, L. Chan, D.M.H. Abram, Z. Zhou, J. Chem. Commun. 1038 (1994).

5. D. Ruiz, P. Reyes, J. Chil. Chem. Soc. 53, 1740, (2008).

6. D. De Vos, I Vankelecom, P. Jacobs. Chiral Catalysis Immobilization and Recicling, Wiley-VCH, 2000; p.1-41, 211.

7. A. Roucoux, J. Schulz, H. Patin, Chem. Rev. 102, 3757, (2002).

8. M. A. El-Sayed, Acc. Chem. Res. 34, 257, (2001).

9. J. A. Widegren, R. G. Finke, J. Mol. Catal. A: Chem. 191, 187, (2003).

10. J. D. Aiken, R. G. Finke, J. Am. Chem. Soc. 121, 8803, (1999).

11. H. Bönnemann, G. A. Braun, J. Chem. Eur. 3, 1200, (1997).

12. J. Dupont, G. S. Fonseca, A. P. Umpierre, P. F. P. Fichtner, S. R. Teixeira, J. Am. Chem. Soc. 124, 4228, (2002).

13. J. U. Kohler, J. S. Bradley, Langmuir. 14, 2730, (1998).

14. H. Bönnemann, G. A. Braun, Angew. Chem. Int. Ed. 35, 1992, (1996).

15. M. Studer, H. U. Blaser, C. Exner, Adv. Synth. Catal. 345, 45, (2003).

16. X. B. Zuo, H. F. Liu, D. W. Guo, X. Z. Yang, Tetrahedron. 55, 7787, (1999).

17. S. Jansat, M. Gomez, K. Philippot, G. Muller, E. Guiu, C. Claver, S. Castillon, B. Chaudret, J. Am. Chem. Soc. 126, 1592, (2004).

18. S. Castillon, C. Claver, Y. Diaz, Chem. Soc. Rev. 34, 702, (2005).

19. M. Dieguez, O. Pamies, C. Claver, Chem. Rev. 104, 3189, (2004).

20. M. Dieguez, O. Pamies, A. Ruiz, Y. Diaz, S. Castillon, C. Claver, Coord. Chem. Rev. 248, 2165, (2004).

21. M. Aghmiz, A. Aghmiz, Y. Diaz, A. Masdeu-Bulto, C. Claver, S. Castillon, J. Org. Chem. 69, 7502, (2004).

22. K. Philippot, B. Chaudret, C. R. Chimie. 6, 1019, (2003).

23. B. Chaudret, C. R. Physique. 6, 117, (2005).

24. J. S. Bradley, E. W. Hill, S. Behal, C. Klein, B. Chaudret, A. Duteil, Chem. Mater. 4, 1234, (1992).

25. D. Zitoun, M. Respaud, M. C. Fromen, M. J. Casanove, P. Lecante, C. Amiens, B. Chaudret, Phys. Rev. Lett. 89, 37203, (2002).

26. M. Axet, S. Castillón,C. Claver, K. Philippot, P. Lecante,, B. Chaudret, Eur. J. Inorg. Chem. 22, 3460, (2008).

27. A. Gual, M. R. Axet, K. Philippot, B. Chaudret, A. Denicourt-Nowicki, A. Roucoux, S. Castillón, C. Claver, Chem. Commun. 2759, (2008).

28. I. Favier, M. Gómez, G. Muller, M. R. Axet, S. Castillón, C. Claver, S. Jansat, B. Chaudret, K. Philippot, Adv. Synth. Catal. 349, 2459, (2007).

29. A. Gual, C. Godard, K. Philippot, B. Chaudret, A. Denicourt-Nowicki, A. Roucoux, S. Castillón, C. Claver, Chem. Sus. Chem. 2, 769, (2009).

30. H. Bönnemann, R. M. Richards, Eur. J. Inorg. Chem. 10, 2455, (2001).

31. D. Han, X. Li, H. Zhang, Z. Liu, J. Li, C. Li, J. Catal. 243, 318, (2006).

32. D. Han, X. Li b, H. Zhang, Z. Liu, G. Hu, Can Li, J. Mol. Cat A: Chem. 
283, 15, (2008).

33. T. Marzialetti, M .Oportus, D. Ruiz, J. L. García Fierro, P. Reyes, Catal. Today. 133, 711, (2008).

34. D. Ruiz, J.L.G. Fierro, P. Reyes. J. Braz. Chem. Soc. 21, 262, (2010).

35. C. Urbina, C. Campos, G. Pecchi, C. Claver, P. Reyes, Molecules. 15, $3428,(2010)$

36. B. Roche, M. Breuer, B. Hauer, P. L. Rogers, Biotechnol. Lett. 28, 841, (2003).

37. P. Reyes, M.del C. Aguirre, I. Melián-Cabrera , M. López Granados, J.L.G. Fierro, Bol. Soc. Chil. Quím. 47, 547, (2002).
38. P. Reyes, H Rojas, J.L.G. Fierro, J. Mol. Catal. A. Chemical. 203, 203, (2003).

39. T. Marzialetti, J.L.G. Fierro, P. Reyes, J. Chil. Chem. Soc. 50, 391, (2005).

40. P. Ellaiah, K.T. Krishna, Indian Drugs. 24, 195, (1987).

\section{ACKNOWLEDGEMENTS}

This work was supported by the FONDECYT project $\mathrm{N}^{\circ} 1061001$. D.R thanks Mecesup for fellowship grant. 